\title{
Na relação entre eugenia e "Educação Physica": a construção das noções eugênicas de beleza
}

\author{
André Luiz dos Santos Silva ${ }^{1}$ \\ Denise Bolsan Berlese ${ }^{2}$
}

\section{RESUMO}

Este estudo discute o processo de construção de uma sensibilidade para a beleza eugênica atrelada à Educação Physica. Para isso, buscamos em "A cura da Fealdade", obra eugenista datada de 1923 e escrita por Renato Kehl, um capítulo intitulado "Saúde, Beleza, Robustez e a Educação Physica". Nessas páginas, encontramos um condensado de imagens e textos que perpassam a ciência e o mito. Identificamos diversos elementos capazes de auxiliar em um processo de educação das noções de corpo. Percebemos subsídios que possibilitam a construção de uma sensibilidade acerca das atividades físicas e sua relação com o ideal eugênico de beleza.

Palavras-chave: Beleza. Eugenia. Educação física

1 Doutor em Ciências do Movimento Humano. Docente dos cursos de Licenciatura e Bacharelado em Educação Física e Pedagogia na Universidade Feevale (FEEVALE). Porto Alegre/Rio Grande do Sul, Brasil. E-mail: andrels@ feevale.br

2 Doutora em Diversidade e Inclusão Social. Docente na Universidade Feevale (FEEVALE). Novo Hamburgo / Rio Grande do Sul, Brasil. E-mail: desniseberlese@feevale.br

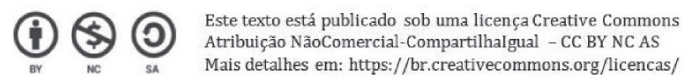


Between eugenia and "Physical Education": the construction of eugenic notions of beauty

\begin{abstract}
This study focuses on the construction of a sensibility for the eugenic beauty harnessed to the Physical Education. Therefore, we searched in 'A cura da Fealdade', eugenist book, which dates from 1923 and was written by Renato Kehl, a chapter entitled "Saúde, Beleza, Robustez e a Educação Physica". In these pages, we found a condensed of images and texts that intertwine science and myth. We identified several elements capable of aiding in a process of education of the body notions. We noticed subsidies which make possible the construction of a sensibility concerning the physical activities and relationship with the eugenic ideal of beauty.
\end{abstract}

Keywords: Beauty. Eugenism. Physical education

En la relación entre eugenia y "Educación Physica": la construcción de las nociones eugenésicas de belleza

\title{
RESUMEN
}

Este estudio discute el proceso de construcción de una sensibilidad para la belleza eugenésica relacionada a la Educación Physica. Para eso, buscamos en "A cura da Fealdade", obra eugenésica fechada el 1923 y escrita por Renato Kehl, un capítulo Ilamado "Saúde, Beleza, Robustez e a Educação Physica". En esas páginas, encontramos un condensado de imágenes y textos que traspasan la ciencia y el mito. Identificamos diversos elementos capaces de auxiliar un proceso de educación de las nociones del cuerpo. Percibimos subsidios que posibilitan la construcción de una sensibilidad acerca de las actividades físicas y su relación con el ideal eugenésico de belleza.

Palabras clave: Belleza. Eugenesia. Educación física

\section{INTRODUÇÃO}

Médico e farmacêutico, Renato Ferraz Kehl (1889-1974) é considerado um dos mais importantes eugenistas brasileiros. Autor de dezenas de livros, Kehl discute em suas obras temas como: educação, maternidade, higiene, saneamento, beleza e educação física. Natural de Limeira, São Paulo, Kehl formou-se em Farmácia, pela Escola de Farmácia de São Paulo, em 1909, e em Medicina, pela Faculdade de Medicina do Rio de Janeiro, em 1915. Membro de um seleto grupo de intelectuais brasileiros no início do século XX, Renato Kehl era detentor de um saber legítimo, cujo status o auxiliou a divulgar a Eugenia (SOUZA, 2006). 
Concebida como um movimento político-científico que tinha por finalidade o aperfeiçoamento da espécie humana, a Eugenia passa a angariar adeptos no Brasil por volta da segunda metade da década de 1910. Anunciada como a solução para o problema das multirraças que conviviam no Brasil, a Eugenia teria fornecido novo ânimo à elite letrada que via com pessimismo o processo de miscigenação. A "ciência da boa raça" seria, portanto, a resposta científica para "curar" os males decorrentes da mistura entre negros, índios, italianos e japoneses (MAIO, 2010; STEPAN, 2005).

Nesse contexto, Renato Kehl funda a Sociedade Eugênica de São Paulo, em parceria com Arnaldo Vieira de Carvalho, em $1918^{3}$. Além disso, passa a publicar seus primeiros livros, cujos conteúdos ensinam modos de ser e se portar a partir dos referenciais normativos da Eugenia. Para tanto, Kehl autoriza-se a discutir diversos temas, entre os quais, a educação física, que, segundo seus textos, teria alto valor para a produção de uma sociedade eugenizada (SILVA, 2008). Ao afirmar a necessidade da prática de exercícios físicos, Kehl ensina sobre os processos naturais do crescimento e desenvolvimento, da fisiologia, da hereditariedade, bem como divulga condutas adequadas e modos de ser. Acreditado pelo saber médico e pelas relações político-intelectuais que construiu, Renato Kehl, ao argumentar em favor da prática sistematizada de exercícios físicos, elege determinadas referências de beleza e, sob a legitimidade científica, gera, como efeito, corpos marginais.

Seguindo essa perspectiva, Renato Kehl escreve "A cura da Fealdade", obra eugenista que trata das questões relativas à beleza eugênica, argumentando que o belo é o resultado do que é normal e saudável. Composto por mais de quinhentas páginas, este livro é dividido em três partes: "1 O HOMEM E A MULHER NORMAES"; "2 A FEALDADE SE EVITA" e, por fim, "3 A CURA DA FEALDADE". Na segunda parte do livro e em meio aos textos e imagens cuidadosamente arranjados, o autor dedica um capítulo especialmente para tratar da relação entre "Saúde, Belleza, Robustez e a Educação Physica".

Em meio a preceitos acadêmico-científicos, Renato Kehl constrói um compêndio pedagógico que procura ensinar os "verdadeiros sentidos da belleza", vinculando-os à prática de exercitação física. Nesse sentido, este artigo discute, a partir do texto "Saúde, Belleza, Robustez e a Educação Physica", o processo no qual Renato Kehl produz e divulga concepções eugênicas de beleza atreladas às práticas de exercitação.

Ao eleger o referido capítulo de livro, Teórico e Metodologicamente, este texto o toma como fonte histórica e o analisa a partir do referencial da História Cultural (CHARTIER, 2001; PESAVENTO, 2003; FALCON, 2002). Desse modo, a narrativa que segue é concebida como uma representação, cuja materialidade é atravessada pelo contexto de sua produção, pelas escolhas metodológicas do autor, pelo modo como as fontes foram organizadas e pelas apropriações das referências. Assim, de acordo com Falcon (2002, p. 30):

3 Apesar de ter fechado suas portas em 1919, a Sociedade Eugênica de São Paulo é considerada um marco no processo de difusão da Eugenia no Brasil (SOUZA, 2006). Sua fundação, apenas dez anos após da sociedade britânica e oito após a francesa, revela-nos consonância entre os cientistas brasileiros e o desenvolvimento científico europeu. 
(...) tais representações [...] são infinitas e teoricamente se equivalem, embora, na prática, o poder e a ideologia tendem a hierarquizá-las ou até suprimir algumas delas. (FALCON, 2002, p. 30)

Por meio desse referencial, a análise da obra de Renato Kehl centra-se nos corpos e nas práticas de Educação Physica, ali descritos, como construções sociais e históricas e, ao percorrer seus argumentos, é possível identificar um conjunto de ideias articuladas a uma rede discursiva, que confere forma e legitimidade a aquilo que Kehl chama de beleza. (GIDDENS, 1997).

\section{A eugenia, Kehl e "a cura da fealdade"}

Conta a história que Licurgo, o então legislador da cidade de Esparta, na antiga Grécia, resolveu colocar em prática um plano de erradicação das deformidades físicas que acometiam sua população. Cada criança nascida com qualquer defeito físico seria lançada de um despenhadeiro para salvar com a morte o ideal de saúde pretendido. Tempos depois, a partir da segunda metade do século XIX, apoiado por uma série de estudos ditos como científicos, Francis Galton teria, segundo Kehl (1923), reeditado as ideias de Licurgo e lançado ao mundo a ciência Eugenia.

A Eugenia, ao propor mecanismos teóricos e metodológicos para fomentar o desenvolvimento da espécie, apoiou-se no controle dos processos agrícolas de cruzamento seletivo, porém, aplicados à espécie humana. Com o surgimento da Genética, em 1900, recebeu forte impulso para afirmar seu status científico (MAYR, 1998).

Como dito, no Brasil, por volta do início da década de dez, esta ciência ganha adeptos ao prometer a "salvação" para o caso de multirraças que aqui se instaurara. Ainda que a elite letrada brasileira olhasse com desânimo para os problemas raciais gerados pela política escravocrata, pela intensa imigração italiana e, posteriormente, japonesa, é justamente esta pluralidade étnica da população brasileira que estimulou uma forma particular da Eugenia neste país. Afinal, negar a mestiçagem seria negar o Brasil.

O colapso gerado pelo barbarismo europeu na primeira grande guerra fortaleceu o surgimento de um 'espírito' nacionalista. Enquanto que, na Europa, a guerra intensificou o medo da degeneração, no Brasil, gerou novo ânimo para o desenvolvimento nacional ${ }^{4}$. Embebidos desse contexto nacionalista, os intelectuais brasileiros, de posse do conhecimento biológico racista, passam a questionar-se quanto à Eugenia, que pregava a raça branca como superior, colocando o brasileiro e o Brasil em condição marginal. Nessa perspectiva, urgia romper com as propostas racistas, dando um tom personalizado às teorias adotadas no Brasil, o que resultou no discurso da singularidade racial brasileira, elevando a miscigenação à categoria de regeneradora racial. Essa mudança no cenário teórico

4 Esse momento político influenciaria a criação de diversas instituições nacionais: Liga de Defesa Nacional (1916), Liga Nacionalista de São Paulo (1917), Liga Brasileira de Higiene Mental (1923) e a Sociedade Eugênica de São Paulo (1918). 
racista não se deu de forma radical - passando a negar postulados raciais -, mas, sim, de forma viesada, o que permitiu ao intelectual brasileiro reconhecer no mestiço fatores de embranquecimento (SANTOS, 2010, SCHWARCZ, 2004).

O processo de urbanização e de industrialização e a emergência de um apelo nacionalista e ufanista, bem como a necessidade de mão de obra mais bem qualificada para o incipiente processo de industrialização demandaram reformas sanitárias (ROCHA, 2003), arquitetônicas e educacionais. Percebido como um povo desprovido de tipo étnico, vicioso, indolente e incivilizado, urgia regenerá-lo por meio de investimentos em diversos campos, entre os quais: a saúde, a educação e o urbanismo. Desse modo, questões como identidade nacional, disciplina e organização racional do trabalho passam a interferir no fazer de educadores, médicos, juristas, arquitetos, etc. (LINHALES; LIMA; OLIVEIRA, 2009).

Áreas correlatas à Educação passam a ser vistas como salvaguardas da "causa cívica", atuando em vistas à saúde, ao disciplinamento e à capacidade de trabalho (LINHALES; LIMA; OLIVEIRA, 2009). Em decorrência disso, na década de 1920, a Educação Física passa a ganhar evidência e representatividade em diversas instâncias, entre as quais: criação do primeiro curso de formação, em $1922^{5}$ (FERREIRA NETO, 1999).

Politicamente, os setores de oposição às oligarquias rurais tinham na ampliação do colégio eleitoral ${ }^{6}$ uma alternativa à república do café com leite. Desse modo, a efervescência política e econômica dos anos 1920 resultou em conflitos armados nos anos de 1922, 1924 e 1926 (MOREIRA, 2003).

Nesse contexto, a Eugenia, enquanto um movimento político e científico altamente normativo, passa a ser vista como capaz de contribuir com os processos de ordem e desenvolvimento nacional (GÓIS JR, 2012). Em que pese a crença nos postulados que hierarquizavam as raças, o movimento Eugênico não pode, entretanto, ser concebido como uníssono e tranquilo. Nesse sentido, havia alguns intelectuais que argumentavam em favor da melhoria racial por meio de boas condições culturais, assim como grupos mais radicais que pregavam práticas como segregação, esterilização e exames médicos pré-nupciais (SILVA, 2007). De acordo com Nalli (2000), a Eugenia de modo geral e a brasileira, em particular, configuraram-se como uma ciência polimorfa, múltipla e heterogênea, constituindo-se como um movimento complexo, cujos embates acadêmicos e políticos permitem uma infinidade de interpretações ${ }^{7}$.

5 Apesar deste marco, a primeira turma não se formou. O curso de organização militar para militares teve suas atividades suspensas em decorrência da revolta de 1922 e apenas em 1929 teve suas funções retomadas (FERREIRA NETO, 1999).

6 Naquele momento, somente sujeitos alfabetizados poderiam votar, neste sentido, a alfabetização colocava-se como uma necessidade (MOREIRA, 2003).

7 O campo da Eugenia, ao longo da história, apresentou diferentes perspectivas de se conceber o "problema eugênico", algumas das quais, bastante dissonantes. Neste sentido, Góis Jr (2002) organiza tais perspectivas em tendências, dentre as quais: Eugenia Galtoniana, Lamarckista etc. Além disso, Souza (2006) aponta que, especificamente na obra de Renato Kehl, é possível ver diferentes concepções do médico em diferentes momentos de sua produção. Este texto toma como fonte uma produção de Kehl, cuja tendência o aproximava mais de uma concepção higienista, indicando melhorias ambientais como importantes fatores para o "aperfeiçoamento da espécie humana". A partir de fins da década de 1920, Renato Kehl passa atribuir a suas obras um caráter mais voltado às práticas radicais a exemplo do que se concebia na Alemanha. Para maiores detalhes indico, além de Souza (2006), Silva (2014). 
Assim, por meio de uma polissêmica gama de concepções acerca da Eugenia, seus autores $^{8}$, abordam em suas produções, temáticas como: saneamento, nutrição, os cuidados gestacionais, puericultura, educação, educação física, entre outros. Assim, Renato Kehl, um de seus maiores expoentes, publica dezenas de livros, entre os quais, destacamos: Bíblia da Saúde (1926a), A Nudez e a Plástica (1926b), Mulheres Bellas (1926c), Como escolher uma boa esposa (1925), O Homem Puro-Sangue (1923b), Como escolher um bom marido? (1923c), Melhoremos e prolonguemos a vida (1922), Eugenia e Medicina Social (1920a), Povo São e Povo Doente (1920b), Exercícios Physicos: A propósito do livro do Dr. Fernando de Azevedo (1920c), Annaes de Eugenia (1919), entre outros.

Em meio a essa vasta produção, como dito, Renato Kehl publica "A cura da fealdade" (1923a), obra que se refere à beleza em uma perspectiva galtoniana, cujo sentido estaria atrelado à harmonia, normalidade e saúde integral. A fealdade, por sua vez, dizia respeito à morbidez, anormalidade, ou 'dysgenia', elementos que estariam além dos aspectos puramente físicos, referindo-se também às anomalias intelectuais e morais. Quanto aos objetivos de seu livro, Kehl fala da importância da propagação dos ideais eugênicos e da união matrimonial precedida de devido exame médico. Segundo Kehl:

Elaborei esta obra impellido por esse ideal; dentro desse critério estabeleci as bases para o aperfeiçoamento somato-psychico dos nossos semelhantes, de conformidade com as aspirações eugênicas (KEHL, 1923a, p. 06).

Em meio a seu percurso argumentativo, as relações entre saúde, beleza e Educação Física são tecidas advogando em favor de um estilo de vida aos moldes eugênicos, dando a entender o que é a verdade da ciência sobre a beleza e de que modos os exercícios físicos auxiliariam nesse processo.

\section{Na fusão mito e ciência: as reconfigurações das noções de belo}

Espartanos e athenienses, indistinctamente, foram os mais perfeitos cultores da arte esplendida do aperfeiçoamento physico. A sua história, escripta com letras de ouro, tem páginas de brilho offuscante, graças à idéa-força, à idéa-belleza que os empolgava. (KEHL, 1923a, p. 322)

As primeiras páginas do texto "Saúde, Belleza, Robustez e a Educação Physica" são escritas a partir de uma aclamada referência à Grécia antiga. Os dizeres do autor sobre a civilização grega iniciam-se com um verdadeiro louvor a este povo que através de seus esforços conseguiu erigir uma raça ariana, pura, branca, perfeita - portanto bela.

Para Kehl, a Grécia constitui uma civilização exemplar em seus campos de Poesia, Arte e Filosofia, no louvor divino à beleza e robustez física, em seu esforço para o aperfeiçoamento humano.

8 Além de Renato Kehl, destacam-se: Fernando de Azevedo, Belizário Penna, Fróes da Fonseca; Octávio Domingues, entre outros. Para maiores informações sobre estes eugenistas, indicam-se Souza (2006) e Stepan, (2005). 
A Grécia, (...), viu nascer, no espaço de dois séculos, uma constelação de homens illustes como nunca mais se verificou em qualquer outro paiz, no mesmo espaço de tempo. Berço de uma raça privilegiada, constituiu o centro da mais alta intellectualidade e cultura do planeta (...) (KEHL, 1923b, s/p.)

Muito mais que louvar os legados de Arte e Filosofia, Kehl evidencia nessa civilização uma série de práticas "pré-eugênicas". A Grécia, descrita por este médico, recebeu contornos da Eugenia, destacando medidas como a seleção matrimonial, políticas imigratórias e extermínio dos degenerados. Esparta destacava-se em meio a essas ações, impedindo e expulsando os estrangeiros para não poluírem, com suas orgias, o sangue e a moral espartanos, selecionando homens e mulheres robustos para a procriação, lançando ao despenhadeiro crianças malnascidas.

Assim, Renato Kehl reconta a história da Grécia antiga, retirando fragmentos de sua cultura para operar uma transposição para seu tempo. Refere-se à beleza, a partir daquilo que se sedimentou como exemplo de perfeição plástica e do modo de ver grego. Retoma um "aglomerado de ideias e imagens simplificadas românticas e popularizadas ao longo do tempo", para então acrescentar novos elementos e direcionar seu fio argumentativo (ALMEIDA, 2001, p. 80).

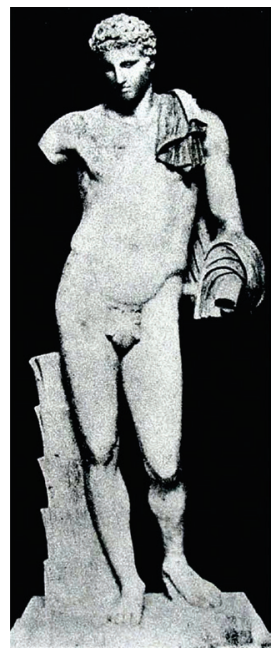

Imagem 1: Antinous

Fonte: Kehl (1923a, p.324)

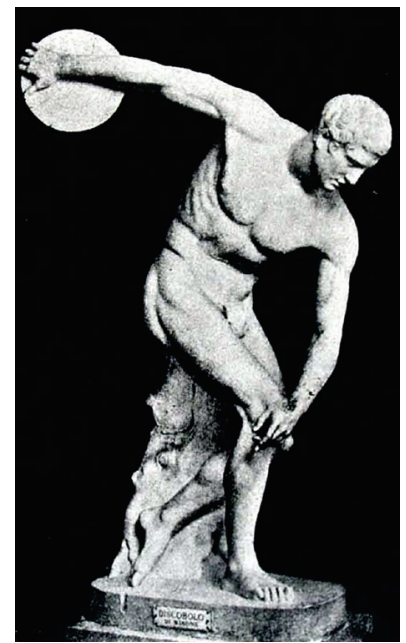

Imagem 2: Discobolo

Fonte: Kehl, 1923a, p.326)

Neste sentido, imagens com as de Antinoüs ${ }^{9}$ e Discobulo ilustram o texto dando materialidade às intenções de Renato Kehl. De modo despretensioso, o autor não menciona

9 Fraga, Goellner e Silva (2011), discutem os modos como a imagem de Antinoüs foi utilizada por Fernando de Azevedo em suas obras inaugurais. Em um período em que Azevedo esteve vinculado ao movimento eugênico brasileiro, apropria-se de Antinoüs como representante máximo da beleza eugênica masculina, esvaziando de sua "história" possíveis "impurezas" que pudessem "manchar" a pureza eugênica a ele associada. 
diretamente as imagens, afinal esculturas tão populares não necessitariam de maiores explicações. O mármore branco ao contrastar com o fundo preto ressalta a perfeições dos corpos manifestas na pele lisa e branca, em pernas torneadas, braços e peitorais suficientemente desenvolvidos. Não há mácula e todas as imagens nos sugerem o que é bom, belo e justo. O recurso que o autor faz das representações de Discóbulo e Antinous, bem como dos textos referentes à Grécia denota um caráter simples, romântico e popular; o que causa um reconhecimento entre imagem/texto e observador/leitor, levando-nos a pensar sobre o uso de uma "lembrança popular de um passado mítico" (ALMEIDA, 2001, p. 80). Entretanto, há momentos em que o autor relativiza estas noções gregas apontando imperfeições daquela civilização bela, limpa e quase perfeita.

Para Kehl, os Gregos, sobretudo os espartanos, eram belos de corpo, cultivavam as práticas corporais, possuíam ideias avançadas, aproximando-os da Eugenia, mas não representavam tipos eugênicos exemplares.

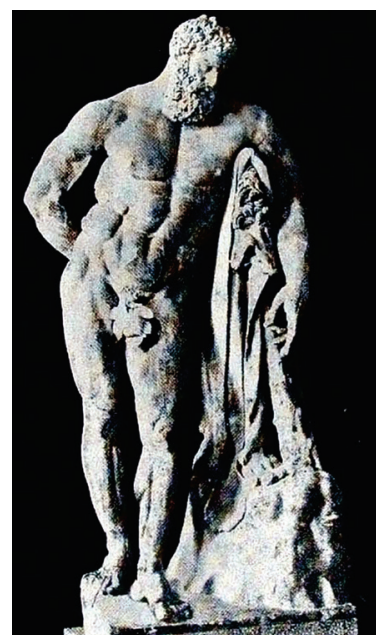

Imagem 3: Hércules

Fonte: Renato Kehl (1923a, p.328)

A exemplo disso, Hércules, filho de Zeus, aparece em meio ao texto dimensionando a disciplina e os cuidados com o corpo, ao mesmo tempo em que materializa as imperfeições do povo grego. Diferentemente de Antinoöus e Descobulo, Hércules com maior volume muscular, seria conhecido por sua força física e bravura. De acordo com a mitologia Grega, a descendência de Hércules deu origem ao povo espartano, que teria herdado suas habilidades de guerra, sua resistência às condições hostis e suas características corporais de força e hipertrofia muscular.

Apesar de louvados pela civilização grega, os espartanos eram vistos por Kehl como povo cuja vida era pobre e as lutas, incessantes. Considerada uma população escravocrata estava habituada ao frio, a alimentos grosseiros e partilhava práticas brutais e impiedosas. 
Os objetivos de perfeição corporal, força, beleza e robustez cegavam os espartanos diante de atrocidades como o infanticídio.

Precisamos ver a Grécia antiga sem a offuscação atordoante dos poemas arrebatadores; precisamos não esquecer o que havia de ferocidade ao lado da grandeza, de barbárie em contraste com a generosidade; precisamos não fazer idéia falsa do heroísmo antigo(...). Os gregos eram bellos de corpo mas só o eram, excepcionalmente, de alma; não representavam, pois, typos eugenicos de homens equilibrados. (KEHL, 1923a, p. 323)

Os gregos, em muitas de suas práticas, deveriam ser louvados, mas não eram considerados, por Kehl, exemplos de sujeitos eugenicamente perfeitos. Os descendentes de Hércules, cultuavam somente o corpo, deixando esquecidos a moral e o intelecto. Eximindo-se do trabalho, este povo legava aos escravos esta prática tão enobrecedora. Mesmo os athenienses, mais instruídos, pacíficos e relativamente mais polidos, não eram considerados exemplo de perfeição galtoniana. Para Kehl, os gregos não haviam contemplado a tríade formada pela perfeição física, moral e intelectual, tão cara aos eugenistas. A beleza, que deve banhar a humanidade, não dizia respeito somente aos belos dotes físicos; devia alcançar a moral e os atributos intelectuais; afinal: muitos seriam os degenerados plasticamente normais (KEHL, 1923a).

Desse modo, devido a essas "imperfeições", Kehl chama a atenção para eugenizar a cultura grega, limpar as imperfeições daquele povo e transportar para o século XX o que de louvável tinha a Grécia, apagando com a eugenia suas imperfeições morais a fim de construir, assim, um povo perfeito: física, moral e intelectualmente.

Apesar de todas as ressalvas, apesar de os tipos gregos não representarem modelos eugenicamente ideais, para Kehl, eram considerados elementos importantes para construção e manutenção dos sujeitos que a eugenia intencionava formar. Nesse sentido, apesar das ressalvas, a beleza emerge em páginas de seu texto, em fragmentos da Antiguidade Clássica, na simetria da arte manifestada em corpos idealizados no mármore.

Ao criticar as práticas do povo grego, ressaltando as possibilidades de aperfeiçoamento via eugenia, o autor opera uma "junção entre elementos do passado e a memória de seu tempo". Pensa e repensa a cultura grega à luz das concepções morais do Brasil no início do século XX, acomodando noções diversas e períodos diferentes numa proposta de embelezamento que vai além da perfeição plástica. Nesse sentido, Almeida (2001, p. 81) sinaliza que:

Devemos lembrar que a Grécia Antiga é uma ficção em imagens e palavras. De há muitos séculos, as ruínas e obras de arte gregas são imagens poderosas sobre as quais se projetam os desejos políticos de diferentes poderes do mundo ocidental e as representações e explicações de artistas e intelectuais. As Grécias certamente nunca se pareceram com essa Grécia Antiga, muito menos a do século XX.

Incorporadas aos desejos e anseios de Kehl e das noções eugênicas de conceber o mundo, as referências gregas prestam-se a um programa político/científico e, para isso, 
constituem-se com um discurso mítico, produzido por um condensado de aspirações e desejos materializados em um conjunto de características atribuídas a um povo (CARVALHO Jr, 2002). Através do ritual de leitura das primeiras páginas do texto "Saúde, Belleza, Robustez e a Educação Física", o mito da beleza é vivificado, reforçado e transformado. O ordenamento das palavras, as referências imagéticas e o argumento entusiasmado ancorado em "chavões" eugênicos ${ }^{10}$ dão a ver um ritual de acesso aos elementos daquela civilização, cujos efeitos acabam por reforçar o mito daquele povo.

O uso que Kehl faz da Grécia antiga, entretanto, não se situa apenas nesta noção de mito $^{11}$. Ao mencionar à cultura grega, o autor remete o leitor a uma série de ideias estabelecidas e sedimentadas como verdade ao longo do tempo. Reforça as noções de uma veracidade intuída e que, como tal, prescinde de evidências científicas e reforça, portanto, o mito da beleza grega.

Renato Kehl, entretanto, associa esse ideal mítico a uma retórica cientificista, conferindo, assim, densidade e capacidade de convencimento a seus argumentos. A Eugenia, desde seus escritos iniciais mostrou-se altamente vinculada ao discurso científico. A exemplo disso, Francis Galton em suas obras inaugurais sobre a Eugenia evidencia a cientificidade que "comprova" suas hipóteses por meio dos encaminhamentos metodológicos e do uso de tratamento estatístico em seus estudos (POLIZELLO, 2008). Nas publicações de eugenistas brasileiros, a menção à eugenia como ciência é constante. De acordo com Renato Kehl: A ciência de Galton é o pedestal da religião que tem por objeto a regeneração integral da humanidade (KEHL, 1935, p.11). Em "A cura da Fealdade" (1923a), Kehl menciona uma infinidade de pesquisadores para argumentar em favor do discurso eugenista e da obtenção da beleza. Especialmente no capítulo "Saúde, Beleza, Robustez e a Educação Physica", isso não é diferente. $\mathrm{O}$ autor reporta-se aos estudiosos das atividades físicas demonstrando um amplo domínio do que diz, reforçando sua noção de pesquisador e intelectual. Entre os vários autores da "Educação Physica" e áreas afins citados, podemos destacar: Fernando de Azevedo, Ling, M. Ducroquet, Heckel, P. Carton, Hawk e Hébert.

Em seu texto, aborda a ginástica sueca e seus benefícios, tendo por ilustração as imagens do livro Gynastique suédoise pédagogique de M. Ducroquet. Kehl ressalta o método natural de Hébert e suas implicações benéficas ao desenvolvimento do organismo humano. Entretanto, cabe apontar que ambos os métodos são discutidos à luz das teorias de crescimento e desenvolvimento de Apert e das noções fisiológicas de P. Carton. Sobre a Ginástica Sueca, Kehl afirma:

Dos dez annos em diante será então incitado o ensino da gymnastica racional, de movimentos lentos, rythmados, entrecortados por intervalos de descanço. (...). O

10 O texto em questão é recheado de frases que se repetem a cada página. Entre elas, podemos citar: "para a força e o progresso da nação"; "normalidade física, moral e intelectual" (KEHL, 1923, p. 323).

11 Usamos neste texto as noções de mito trazidas por: Carvalho (2001), a qual diz que o mito surge como verdade intuída, percebida de maneira espontânea sem necessidade de provas, o que contrapõe o mito à ciência. De modo semelhante, Carvalho Júnior (2002) refere-se à mito como um condensado de aspirações de um povo, materializações de características, ânsias e desejos. 
methodo gymnastico de Ling ou gymnastica sueca repousa neste salutar princípio. (...). Os effeitos da sua prática são apreciáveis, porque é um methodo scientifico, pedagogico e orthopedico, neste último caso útil para corrigir defeitos de conformação. (KEHL, 1923a, p. 329)

Muito além de informação, as páginas de "A cura da fealdade" usam de argumentos científicos para legitimar e construir uma percepção de beleza que perpassa as atividades físicas. Entretanto, o tom do discurso neste capítulo não se refere àquilo que irá ou não eugenizar $^{12}$ determinado ser. A grande preocupação do discurso médico no momento de "A cura da fealdade" está em disseminar hábitos e formas de pensar saudáveis, haja vista as condições de miséria, doenças, falta de saneamento urbano, analfabetismo e o contexto marcadamente nacionalista que impediriam ações mais ostensivas para eugenizar a população.

A tônica do discurso no capítulo "Saúde, Beleza, Robustez e a Educação Physica" direcionou-se a criar um estilo de vida eugênico, no qual estariam envolvidos hábitos higiênicos e práticas saudáveis de exercitar o corpo.

A estatuária grega, a importância da "Educação Physica", o discurso científico e todas as imagens presentes em seu texto prestar-se-iam a um "papel pedagógico"; uma educação dos sentidos, das noções de belo e feio, ou ainda "difundir a escolha normativa da beleza" (SCHPUM, 1999; SOARES, 2005). De acordo com Miranda (2005, p. 05):

Dizer que algo participa da educação é mostrar que determinado entendimento, sentimento ou julgamento não é natural, ou seja, aprendemos a tê-los. No caso das imagens não vemos porque temos olhos, vemos porque aprendemos a olhar.

Nesse sentido, por meio de um processo pedagógico, Renato Kehl produz, em seu texto, um material didático que ensina a reconhecer e apreciar a beleza eugênica. Ao mesmo tempo em que apresenta e reforça a beleza grega como um mito, Kehl apoia seu texto em bases científicas e assim confere a seus argumentos uma densidade peculiar. $\mathrm{O}$ uso do mito aliado ao discurso científico confere vulto a seus dizeres em uma teia cuidadosamente tecida, unindo o desejo de retorno à beleza grega por meio das diretrizes científicas da eugenia. A organização de seu discurso, o fio condutor de seus argumentos, leva o leitor a educar seu olhar para aquilo que define ser uma beleza eugênica. Deixa, a partir de tudo o que foi dito, mesmo que de forma germinal, concepções de beleza que passam pela eugenia e pela "Educação Physica".

12 Eugenizar refere-se à prática capaz de erradicar imperfeições via cruzamento seletivo. 


\section{REFERÊNCIAS}

ALMEIDA, Milton José de. A liturgia olímpica. In: SOARES, Carmen Lúcia (Org.). Corpo e História. Campinas: Autores Associados, 2001. p. 79-108.

CARVALHO JÚNIOR, Dario de Barros. A morte do herói: Introdução ao estudo de sobrevivência de modelos míticosnas Histórias em Quadrinhos. 2002. 101 f. Dissertação (Mestrado) - Curso de Educação, Unicamp, Campinas, 2002.

CARVALHO, Yara Maria de. O mito da atividade física e saúde. 3. ed. São Paulo: Hucitec, 2001.

CHARTIER, Roger. Textos, impressão, leitura. In: HUNT, Lynn (Org.). A Nova História Cultural. São Paulo: Martins Fontes, 1992. p. 211-238.

FALCON, Francisco José Calazans. História Cultural: Uma visão sobre a sociedade e a cultura. Rio de Janeiro: Campos, 2002.

FERREIRA NETO, Amarílio. A pedagogia no exército e na escola: a educação física brasileira (1880-1950). Aracruz: Facha, 1999.

GIDDENS, Anthony. Modernidade e identidade pessoal. Oeiras: Celta, 1997.

GOIS JUNIOR, Edivaldo. Ginástica, higiene e eugenia no projeto de nação brasileira: Rio de Janeiro, século XIX e início do século XX. Movimento, Porto Alegre, p.139-159, dez. 2012.

KEHL, Renato. Lições de Eugenia. Rio de Janeiro: Livraria Francisco Alves, 1935.

. Bíblia da saúde (hygiene). Rio de Janeiro: Francisco Alves, 1926a.

. A nudez e a plástica. Revista da Semana, Rio de Janeiro, p.11-12, jun. 1926b.

. Mulheres bellas. Revista da Semana, Rio de Janeiro, p.16-19, jun. 1926c.

. Como escolher uma boa esposa? Rio de Janeiro: Pimenta de Mello e C, 1925.

A cura da fealdade: Eugenia e medicina social. São Paulo: Monteiro Lobato \& Co-editores. 1926a.

. O homem puro-sangue. Gazeta de Notícias: Rio de Janeiro, p.9-10, jan. 1923b.

. Como escolher um bom marido? Correio da manhã. Rio de Janeiro, p.13-14. Jan.

1923c.

. Melhoremos e prolonguemos a vida: a valorização eugênica do homem. Rio de Janeiro: Livraria Francisco Alves, 1922.

. Eugenia e Medicina Social: problemas da vida. Rio de Janeiro: Livraria Francisco Alves, 1920a.

. Povo são e povo doente: algumas considerações e dados anthropométricos. Rio de Janeiro: Publicações Brasil - Médico, 1920b.

. Exercícios Physucis: a propósito do livro de Dr. Fernando de Azevedo. O jornal. Rio de Janeiro. p. 9. Jan. 1920c.

. Annaes de Eugenia: Sociedade Eugênica de São Paulo. São Paulo: Editora da Revista do Brasil, 1919.

LINHALES, Meily Assbú; LIMA, Cássia Danielle Monteiro Dias; OLIVEIRA, Liliane Tiburcio de. Médicos e Educadores na "Secção de Educação Physica e Hygiene" da Associação Brasileira de Educação. XVI CONBRACE E III CONICE, Salvador, p.84-96, set. 2009. 
Disponível em: < http://www.rbceonline.org.br/congressos/index.php/CONBRACE/ XVI/paper/viewFile/489/825>. Acesso em: 16 nov. 2014.

MAIO, Marcos Chor. Raça, doença e saúde pública no Brasil: um debate sobre o pensamento higienista no Brasil (1870-1930). In: MAIO, Marcos Chor; SANTOS, Ricardo Ventura (Org.). Raça como Questão: História, Ciência e Identidade no Brasil. Rio de Janeiro: Fiocruz, 2010. p. 51-82.

MAYR, Ernest. O Desenvolvimento do Pensamento Biológico: diversidade, evolução e herança.. Brasília: Editora da Unb, 1998.

MIRANDA, Carlos Eduardo Albuquerque. A fisiognomonia de Charles Le Brun: a educação da face e a educação do olhar. Pró-posições, Campinas, p.27-39, maio 2008.

MOREIRA, Antônio Flávio Barbosa. Currículos e Programas no Brasil. São Paulo: Papirus, 2003.

PASAVENTO, Sandra Jatahy. História \& História Cultural. Belo Horizonte: Autêntica, 2003.

POLIZELLO, Andreza. Modelos microscópicos de herança no século XIX: a teoria das estirpes de Francis Galton. Filosofia e História da Biologia, São Paulo, p.41-54, 2008.

ROCHA, Heloísa Helena Pimenta. A higienização dos costumes: Educação escolar e saúde no projeto do Instituto de Hygiene de São Paulo (1918-1925). Campinas: Marcado das Letras, 2003.

SANTOS, Ricardo Ventura. Mestiçagem, Degeneração e a Viabilidade de uma Nação: debates em antropologia física no Brasil (1870-1930). In: MAIO, Marcos Chor; SANTOS, Ricardo Ventura (Org.). Raça como Questão: História, Ciência e Identidade no Brasil. Rio de Janeiro: Fiocruz, 2010. p. 83-108.

SCHPUN, Mônica Raisa. Beleza em jogo: Cultura física e comportamento em São Paulo nos anos 20. São Paulo: Boitempo, 1999.

SCHWARCZ, Lilia Moritz. O Espetáculo das raças: cientistas, instituições e questão racial no Brasil. São Paulo: Editora Companhia das Letras, 2004.

SILVA, André Luiz dos Santos; GOELLNER, Silvana Vilodre. Sedentárias e Coquettes à margem: corpos e feminilidades desviantes na obra de Renato Kehl. Pensar A Prática, Goiania, p.251-259, set. 2009.

SOARES, Carmen Lucia. Imagens da Educação no Corpo. Campinas: Autores Associados, 2005.

SOUZA, Vanderlei Sebastião de. A Política Biológica como projeto: a "Eugenia Negativa" e a construção da nacionalidade na trajetória de Renato Kehl (1917-1932). 2006. 220 f. Dissertação (Mestrado) - Curso de História, Carlos Oswaldo Cruz, Rio de Janeiro, 2006. STEPAN, Nancy Leys. A hora da Eugenia: raça, gênero e nação na América Latina. Rio de Janeiro: Fiocruz, 2005.

Recebido em: Outubro/2017

Aprovado em: Dezembro/2017 